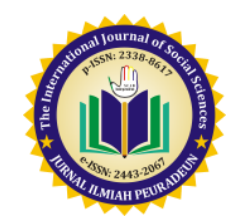

\title{
THE DEVELOPMENT OF SOCIAL AND MORAL RESPONSIBILITY IN TERMS OF RESPECT FOR THE RIGHTS OF OTHERS
}

\author{
Katie J. Hughes and Laura Batten \\ Department of Psychology, University of Southampton, United Kingdom
}

Received: Sept 24, 2015

Accepted: Nov 7, 2015

Published: May 28, 2016

Article Url: https://journal.scadindependent.org/index.php/jipeuradeun/article/view/93

\begin{abstract}
Social responsibility suggests that an individual has responsibility to the community or society in terms of choices about behaviors. Moral responsibility implies a knowledge and understanding of 'right' and 'wrong' and the ability and willingness to behave morally. These debates reflect the uncertainties about how moral and social responsibility can be conceptualized and promoted within modern societies. Adrift from moral certainties and wary of merely promoting dominant cultural norms, the role of moral reasoning and the ability to rationally choose between moral values is fore fronted, but leaves us with a concern that such choices may lack a coherent value base or 'morality'. The debate leaves us with the question as to how we promote moral and social responsibility in young people as part of their learning in higher education in ways that promote moral reasoning but also develop values and ethical stances that go beyond, and can contest, the social norms of the times.
\end{abstract}

Keywords: Moral, Education, Social, Responsibility, Across Cultures 


\section{A. Introduction}

The Crick Report states that the development of social and moral responsibility is a pre-requisite of citizenship, in respect of a required understanding of the consequences of one's actions and the impact of these actions on others. And social and moral responsibility is one of the three themes of citizenship education outlined in the Crick Report (1998). Underpinning this theme is the sense that there needs to be a much clearer focus on developing social and moral responsibility, in terms of respect for the rights of others and the relationship between the individual and the community, in young people. As such, Crick argued that citizenship education requires young people to learn about moral values and to develop their ability to apply these in practice (1998). However, on publication of the report it was suggested that this theme was possibly the most controversial of the three, because while a moral dimension to citizenship education avoids the 'dry' civic approach, it also begs the question as to which moral values, in a pluralist society, young people should be learning (Pyke, 2002).

Social responsibility suggests that an individual has responsibility to the community or society in terms of choices about behaviour. Moral responsibility implies a knowledge and understanding of 'right' and 'wrong' and the ability and willingness to behave morally. As such, citizenship education in this area focuses on developing individuals' ability to act as moral agents in their choices, intentions and actions. One aspect of this is legal responsibility i.e. the responsibility of a citizen to act within the law. However, the concept of social responsibility implies a more active role than remaining law-abiding, encompassing the notion that individuals should support and protect their societies' interests and that they should be more broadly accountable to their communities for their actions.

\section{B. Social and Moral Development and Higher Education}

Sandolow (1991) states that 'contemporary notions of morality are likely to regard it as a human construct', suggesting that the current debate focuses not so much on absolutes about what is moral or not, but on how we deal with questions about what has been constructed. With little consensus about what is morality, educationalists are left with the 
unenviable task of supporting the development of social and moral responsibility without a certain framework on which to base this process. In HEIs the development of social and moral responsibility through the transmission of values has been seen as problematical since the certainties of religious doctrine have diminished since the nineteenth century.

However, some believe that the role of HEIs in this process has become central because of that very uncertainty. Sandolow (1991) argues that as both large influential conglomerates and as centres of education, HEIs have a role in supporting moral development. Sandolow adopts Feinberg's (1968) view that collective social responsibility is the concern of large institutions and that while their primary purpose may not be to pursue social justice; it is still part of their role. In addition, the view that HEIs should be concerned with moral issues persists, implying that students need to be viewed as members of a community and not just as customers.

Wilcox and Ebbs (1992) echo this view, stating that, as HEIs are a source of knowledge they are also powerful and capable of influencing social and economic life. Harkavy (2006), however, suggests that often the rhetoric of HEIs does not match outcomes. While HEIs may support the promotion of citizenship values and practices, the commercialisation of higher education 'powerfully legitimises and reinforces the pursuit of economic self-interest by students' (Harkavy, 2006: 14). This begs the question as to whether higher education has moved in purpose from the ethical, social and character development that was evident in the past, to a focus on discipline-led training for specific employment purposes (Holland, 1991).

This implies that students may have 'utilitarian' purposes for entering higher education, focusing on achieving qualifications for a career, rather than a broader educational experience (Jones and Thomas, 2005). This is confirmed by Kuh (2005) cited in Hersch and Schneider (2005), who reported that in the previous decade there was a significant decrease in the number of students who had reported developments in their values and ethics during their time in higher education. In addition, Cleaver et al (2005) found that schools encountered significant difficulties in involving pupils in decision-making, which resonates with the experience of HEIs. 
In consumer -driven market economies, in which, the distribution of wealth, power and status dominate, it is difficult to see where the notion of individual moral responsibility may lie. Sandolow (1991) argues this point and suggests that HEIs are critiqued from both conservative and liberal standpoints for neither teaching the ethics of individual moral responsibility or a commitment to improving society through social change. Carr (1999: 26) proposes that there are two questions involved: the 'proper direction' of moral education and whether what happens in our educational institutions can improve public behaviour. The problem is when moral education focuses only on issues of social order and the inculcation of desirable social habits. Although this is generally seen as part of the moral educational process, it is problematical to consider an education that goes beyond this and tackling issues of 'absolute and universal moral significance'.

Moral messages are part of what takes place in HEIs and as they cannot be ignored, these messages must not be left to chance (Colby et al., 2003). Hersch and Schneider (2005) suggest that concerns about imposing moral values on students and the fragmentation of ethical certainties may suggest that others' social and moral responsibility is "none of our businesses".

However, the authors discount this view on the basis that whether formally planned or not, being part of a higher education community will convey moral values and influence the development of students' social and moral responsibility. If this is the case, then HEIs need to consider the ways in which that influence is best expressed. Wilcox and Ebbs (1992: 1) promote the view that it is important to analyse the ethics of the ethos of the whole institution, in terms of culture, customs and practices across the institutional structures. The key issue is the impact of this ethos on the quality of life.

As such, 'Responsibility for individual and social welfare is part of the institutional landscape, a daily occurrence manifested in decision making on all levels of the college or university and in the goals toward which the decision making is directed'. The quality of the ethical environment is significant to students' overall experience of higher education and the ways in which they negotiate ethical issues and their own experiences.

\section{The Concept of Morality}

There is no doubt that the concept of morality is disputed, but Wilson (1990) reminds us that there is a difference between words and concepts. While 
'moral' may mean different things in different contexts, the concept of morality is common. Hersch et al (1980: 82) state that morality has three elements: caring (involving social motivation and social knowledge); judging (making judgements about competing moral issues in relation to a consistent moral principle); acting (an action not being moral or immoral in itself but dependent on the caring and judging it is based on).

However, defining morality is complex and Wilson draws on Plato and Aristotle's deliberations to suggest that 'the central use of 'moral' refers to a certain set of underlying dispositions, to the basic ecology....of human desires, emotions and deeds.' Wilson goes on to argue that morality is not something we can accept or reject as suggested by Warnock (1971) because it underpins all human activities, even those concerned with non-moral issues.

Eshelman (2004) states than any theory of moral responsibility should discuss the concept of moral responsibility; the criteria for being a moral agent; the conditions under which moral responsibility is properly applied (where an agent has acted with free will and is able to make choices) and 'objects of responsibility ascriptions' (those things that we can ascribe moral responsibility to such as actions or non-actions).

A key part of this discussion is how morality can be determined. Concerns about determining the moral virtues have given way to focusing on trying to determine what moral behaviour is and what is not and criteria or principles for determining what is right and what is wrong. These questions have a different significance since the hegemony of the church in determining absolute moral values gave way to more individualistic and subjective views of values during the Reformation (Carr, 1999). Subsequent theories of morality focus more on the role of moral reasoning in achieving human goals rather than any absolute concept of moral values.

As such, normative ethical theories emerged; dealing with efforts to determine how right and wrong can be classified and translated into rules for human conduct. Consequentiality theories hold that it is the consequences of an action that determine its morality, not the character of the action itself. So the morality of an action is determined retrospectively, 
based on the outcomes of the action, and a morally positive action is one that produces good consequences (Eshelmen, 2004).

Deontological theories focus on the morality of an action as inherent in the act itself and not in the outcomes of that act. Locke's theory that humans have inalienable natural rights, which determine codes of social behaviour, exemplifies this. Locke argued that breaches of these inalienable rights would be classified as 'wrong' and upholding these rights would be classified as 'right', regardless of outcome. Kant also focused on the morality of action themselves rather than outcomes, arguing that moral acts are what any rational being could envisage as being universal moral laws, following on from Hobbe's assertion that moral behaviour is that which unbiased others would agree was moral. Kant suggested that the test for the morality of an action was the categorical imperative i.e. that any such action could become a universal moral law. If this should not be the case, then the action would not be seen as moral.

The issue that arises from both these theoretical bases is the implication that a value judgement about what is 'right' and what is 'wrong' or what a 'good' outcome is or a 'bad' outcome has to be made. This begs the question as to whether all assumptions of morality are subjective and relative. Ayer (1948) argues that there is no 'truth value' to moral statements as they merely reflect the individuals' moral beliefs and are entirely subjective. He suggested that moral discussion focuses on the advisability of accepting or rejecting an action or viewpoint but 'discredits the logical authority of moral statements because the criteria for logical verification cannot be established' (McPhail, 1982: 21).

If we, then, reject the existence of universal moral laws, then are all moral standpoints individually or socially determined within specific cultural contexts? If this is the case, then the promotion of morality through education could be viewed as part of the socialisation of an individual into a group (community) by inculcating a particular culturally determined view or perspective of what morality is. McPhail (1982) argues that morality can stand beyond the social norms and therefore include both inculcation into these norms and evaluation and criticism of these. However, this discussion brings us back to the basic question of why we should be moral in terms of concern for others and their needs, and whether incentives to morality are intrinsic or relate to personal gratification or gain. 
Hard determinists argue that free will is impossible in a world where events and actions are causally determined by a chain of prior occurrences, bringing into question the ability of individuals to make rational and free choices about their actions. Without free will, the individual cannot be held morally responsible for actions that are predetermined and outside that individual's control.

The debate about whether the concepts of free will and determinism can be held simultaneously has dominated discussion about whether humans can be held responsible for their actions. Compatibilists argue that these two apparently opposing concepts can be reconciled as behaviour needs to be determined, rather than random, for the actor to be held responsible for it. Free will is dependent on choices being deliberately and consciously made and the existence of choice, in that the actor could have acted otherwise than they did. The question then arises as to whether free will does exist. Can individuals really make choices and act freely? Sartre theorized that freedom of choice and action are the only criteria for moral behaviors. He argued that there can be no guidance or prescription for moral behaviors and choices, but that the individual acts morally if they choose their actions freely. Sartre distinguishes his views not by emphasising free choice as a central tenet of morality, but because he considered this was a sufficient criteria.

Honderich suggest two models of moral responsibility. If we are able to make choices and are responsible for these (voluntariness and origination) then we have free will but this is incompatible with determinism. If we are only able to make choices but cannot be responsible for these (voluntariness only) then we have free will that is compatible with determinism.

Honderich (1988) argues the significance of consequentialism, suggesting through his 'Principle of Humanity' that morality is associated with behaviors that helps others out of 'bad' lives. Morality is therefore linked to our actions or omissions in terms of this process as we have moral responsibility for 'bad' lives. Decision-making on whether an action is moral or not should be based on the consequences of that action only 
(Anscombe, 1958). This begs the question of how the morality of specific actions can be judged in terms of consequences as these may be different for different individuals, groups or communities affected by such actions.

Raillon (1984) argues that there can be tension between the individuals' interests and the interests of the community in determining the morality of an action, where the outcomes differ for each. He suggests that individuals will be more concerned with the outcomes for themselves and those close to them than they will for the wider community. Downie (1964) also suggested that the extent of moral responsibility may be determined according to the social roles that individual adopt within their social context. Social roles may impact on the individual's freedom to act from choice. For example, an individual may choose not to kill another human as part of their freely chosen moral behaviors, but may kill others in the social role of a combatant in war.

Eshelman (2004) suggests that the most recent views on morality focus on responsibility as attributability and responsibility as accountability. Attributability is related to the notion of self and accountability to the concept of moral responsibility in a social context so that a behavior is 'governed by an interpersonal normative standard of conduct that creates expectations between members of a shared community.' Within this concept, holding someone responsible is essentially a social act, based on belonging to a shared moral community. Moral responsibility can be seen in this context as the extent to which individuals support or undermine the well-being of the community, suggesting that morality is indeed a culturally-determined set of norms and conformity to these is moral behaviors. This view is contested on the basis that we must not equate social conformity with morality, because one of the key aspects of developing morality is the development of moral reasoning.

These debates reflect the uncertainties about how moral and social responsibility can be conceptualized and promoted within modern societies. Adrift from moral certainties and wary of merely promoting dominant cultural norms, the role of moral reasoning and the ability to rationally choose between moral values is fore fronted, but leaves us with a concern that such choices may lack a coherent value base or 'morality'. The debate leaves us with the question 
as to how we promote moral and social responsibility in young people as part of their learning in higher education in ways that promote moral reasoning but also develop values and ethical stances that go beyond, and can contest, the social norms of the times.

\section{Educating for Social and Moral Responsibility}

Hersch et al (1980:14) suggest that the purpose of moral education in the nineteenth century was to promote a 'narrow form of socialization'. However, in the twentieth century this narrowness was challenged by philosophers such as Dewey $(1909 ; 1938)$ who argued that morality was a dynamic not static concept, linked to the changing values of modern democracies. Dewey believed that moral education needed to be rooted in the development of reasoning, not in training children to be dutiful to fixed moral rules. As such, Dewey's arguments suggest that moral education and education per se are the same thing as they both involve the use of reason to resolve issues.

However, liberal educationalists such as Dewey were challenged in their belief that learning the ability to rationally reflect on values was sufficient to develop moral responsibility. According to Carr (1999) liberal educationalists in a secular world sought to promote 'rational moral autonomy' to prepare individuals' for their role in an individualistic market economy and to maximise the chances of positive life choices. This notion of morality is rooted in concepts of individual rights and reciprocal relationships between individuals rather than the absolute moral values of previous times. Jonathan (1999) suggests that liberal moral education supports the development of individuals as moral agents who are equipped to reflect on the range of values they encounter and make considered moral judgements about these. Kohlberg (1981) supports this approach through his theory of moral development. Theorising that moral development is achieved through stages in progress towards increasingly sophisticated moral reasoning signifies that such moral reasoning is the 'central feature of morality and moral education.' (Straughan 1982:19).

Wilson (1990) argues that moral relativism does not make all values and beliefs arbitrary. He suggests that the answer to problems of relativity in moral thinking should be answered by closer focus on the 
processes of thinking about and rationalising moral issues. However, Carr (1999: 38) concludes that liberal moral education, with its tolerance of a wide range of moral perspectives, excluding those which infringed on individual rights, failed to establish or explore 'which human goals are worthier of pursuit than others'.

Jonathan (1999) also states that the development of critical reasoning is not sufficient in moral education as it does not in itself provide the framework upon which to develop and structure moral values. However, responses to the perceived crisis of moral decline vary. Straughan (1982: 9) suggested that the perception that a moral vacuum had entered the classroom, as the declining influence of religion severed society from moral certainties, was a flawed concept. Straughan argues that the 'moralistic argument' is untenable as it is not possible to educate for moral certainties or to teach children 'to be good'. Straughan suggests that educators affect value neutrality and value clarification to support the development of individual moral reasoning, in fact values are transmitted through in all educational institutions through pedagogical choices and practices.

Wilcox and Ebbs (1992) suggest that the learning community is the key element in supporting the 'scholar teacher/researcher' to balance individual and group needs as they negotiate 'teaching, discovery, application and integration.' The learning community provides coherence to the experience of members and supports the development of an ethical basis for the institution as a whole. Learning communities can be described as: 'an ideal type of higher education culture that seeks to overcome current tendencies toward individual alienation and intellectual fragmentation with regard to present academic specialization and special interests'.

It is clear that the role of HEIs must go beyond simply supporting the development of rational thinking in students in value-free ways. The culture and ethos of the institution needs to promote the development of social and moral responsibility in more active and committed ways, which support the student to negotiate the competing demands of self and others.

\section{E. Ethos and Active Learning}

Dewey $(1909 ; 1938)$ strongly advocated active learning approaches to moral education arguing that participation and reflection were the keys to 
learning moral values. In this way, learning about morality becomes practicing moral behaviour in a variety of social situations. This view has implications for education in social and moral responsibility today, as according to Dewey, this simply cannot be achieved through classroom teaching, but must be achieved through collective participation in meaningful activities and institutions, which promote learning through experience, enquiry and reflection.

Even if the teacher introduced concepts like democracy, justice, respect for others, and human rights, if the classroom and school structure continued to model and enforce authoritarian social relations, no effective learning would take place.' (Hersch et al, 1980:21)

McPhail (1982) suggests that Dewey's ideas are relevant to pluralist societies in which moral values and bases may be contested and the rights of the individual and groups may at time conflict. Sandolow (1991) also suggests supporting student 'character development' through active learning that develops both student knowledge and their ability to think rationally, as a way forward from the apparent impasse in HEIs around moral development.

Farbo (2006) also supports the introduction of engagement pedagogies but warned that they must not be merely seen as instructional innovation. HEIs must create the conditions for learning about moral and social issues through their structures and functions in order for this to be a meaningful experience. In his review of Dewey's work Smith (2001) suggests that educational institutions need to reflect the ideals that they are supporting in their own structures and functions, by democratising relationships between students and teachers. Smith also cites Winch and Gingell (1999) who state that 'if schools exist to promote democratic values it would appear that they need to remove authoritarian relationships.' (Smith, 2001). It is difficult to see how this does not also apply to HEIs. Democratic relationships are only one aspect of effective learning communities for citizenship; Hersch and Schneider (2005) suggest that there needs to be a significant and 'pervasive' cultural change to ensure that HEIs can educate for moral responsibility.

Nixon suggests that the way forward is a 'new Aristotelianism' (2004: 115) informed by both the Socratic idea of negative wisdom and the 
moral imperative to take the 'right action'. Negative wisdom involves the questioning of false assumptions and therefore involvement in rational debate, whereas the 'right action' implies involvement in social and community issues and living a 'good' life. Combining these two notions suggest that a 'good' life can be lived despite the lack of moral certainties. Within this notion, learning is associated with agency and social engagement. Students need to practise social and moral responsibility through engaging with others in learning about their world, rather than learn about citizenship issues in theory. Pedagogies that promote rational debate and reflection need to be promoted in the context of exploring social and moral issues in 'real life' contexts. In this way learning becomes the medium for social engagement and participation.

\section{F. Conclusion}

The effectiveness of HEIs in supporting the development of students' social and moral responsibility rests on an holistic approach, encompassing the institutional ethos; culture; structures and pedagogies. While active learning focusing on engagement and rational debate can support the development of students' ability to recognise and consider ethical issues, the environment in which this takes place must reflect an ethos that promotes positive relationships and values such as respect, honesty and caring.

Mass market, consumerist approaches to higher education may fail to provide students with the necessary environment in which social and moral development can take place effectively. Students need opportunities to engage in learning communities that both respect their individuality and support their involvement with others in mutually created learning experiences that nurture debate and challenge their thinking.

\section{Bibliography}

Carr, D. (1999). Cross questions and crooked answers: contemporary problems for moral education. In J. Mark Halstead and T. H. McLaughlin Education in Morality London: Routledge 
Cleaver, E., Ireland, E., Kerr, D. and Lopes, J. (2005). Citizenship Education Longitudinal Study: Second Cross-Sectional Survey 2004. Listening to Young People: Citizenship Education in England (DfES Research Report 626). London: DfES.

Colby, A., Ehrlich, T., Beaumont, E., and Stephens, J. (2003). Pedagogical strategies for educating citizens. In A. Colby et al., Educating citizens: Preparing America's undergraduates for lives or moral and civic responsibility San Francisco: Jossey-Bass.

Dewey, J. (1909). Moral Principles in Education Boston: Houghton Mifflin Company

Dewey, J. (1938). Experience and Education New York: Collier Books

Downie, R.S. (1964). Social roles and moral responsibility Philosophy 39(147): 29-36

Feinberg, J. (1968). Collective Responsibility, Journal of Philosophy, vol. LXV, no. 21 (November 1968), pp. 222-51.

Harkavy, I. (2006). The role of universities in advancing citizenship and social justice in the $21^{\text {st }}$ century. Education, Citizenship and Social Justice, 1 (1), 5-37.

Hersch, R. H., Miller, J. P. and Fielding, G. D.(1980). Models of Moral Education New York: Longman Inc.

Hersh, R.H. and Schneider, C.G. (2005 Summer/Fall) Fostering Personal and Social Responsibility on College and University Campuses Liberal Education, 6-13. (B)

Holland, J. R. (1991). Moral Values in Higher Education. In D. L. Thomson (ed) Moral Values and Higher Education New York: Suny Press

Honderich, T. (1988). The Consequences of Determinism: A Theory of Determinism Vol. 2 London: Clarendon Paperbacks

Jonathan, R. (1999.) Agency and contingency in moral development and education. In J. Mark Halstead and T. H. McLaughlin Education in Morality London: Routledge

Jones. R. \& Thomas, L. (2005). The 2003 UK Government Higher Education White Paper: a critical assessment of its implications for the success of the widening participation agenda. Journal of Education Policy, 20 (5), 615-630

Kohlberg, L. (1981). The Philosophy of Moral Development: Moral Stages and the Idea of Justice. New York: Harper \& Row Publishers 
McPhail, P. (1982). Social and Moral Education Oxford: Blackwell

Nixon, J. (2004). Learning the Language of Deliberative Democracy. In M. Walker and J. Nixon (eds.) Reclaiming Universities from a Runaway World. Buckingham: Open University Press.

Pyke, N. (2002). Citizenship: Critical thinking not propaganda Independent 27.9.02

Raillon, P. (1984). Alienation, Consequentialism and the Demands of Morality Philosophy and Public Affairs, Vol. 13, 2, pp134-171

Saifullah. (2015). The Internalization of Democratic Values into Education and Their Relevance to Islamic Education Development (Synthetic, Analytic, and Eclectic Implementation of John Dewey's Thoughts). Advanced Science Letters, Journal of Computational and Theoretical Nanoscience, 21 (7), pp. 2301-2304, DOI: 10.1166/asl.2015.6257

Salami, S. (2015). Implementing Neuro Linguistic Programming (NLP) in Changing Students' Behavior: Research Done at Islamic Universities in Aceh. Jurnal Ilmiah Peuradeun, 3(2), 235-256.

Sandolow, T. (1991). The Moral Responsibility of Universities. In D. L. Thomson (ed) Moral Values and Higher Education New York: Suny Press

Straughan, R. (1982). Can we teach children to be good? Milton Keynes: Open University Press

Straughan, R. (1989). Beliefs, Behaviour and Education London: Cassell Education

Strawson, P. F. (1974). Freedom and Resentment London: Methuen

Warnock, G. J. (1971). The Object of Morality London: Methuen

Wilcox, J.R. and Ebbs, S.L. (1992). The Leadership Compass. Values and Ethics in Higher Education ASHE-ERIC Higher Education Rep. No. 1

Wilson, J. (1990). A New Introduction to Moral Education London: Cassell Education

Winch, C. and Gingell, J. (1999). Key Concepts in the Philosophy of Education. International Review of Education, 46 (3-4), 351-352. London: Routledge.

Yusoff, M. Z. M., \& Hamzah, A. (2015). Direction of Moral Education Teacher To Enrich Character Education. Jurnal Ilmiah Peuradeun, 3(1), 119-132.

ZA, T. (2014). Islamic Studies dalam Pendekatan Multidisipliner (Suatu Kajian Gradual Menuju Paradigma Global). Jurnal Ilmiah Peuradeun, 2(2), 211-234. 